\title{
Tensile, Compression and Fracture Properties of Thick-Walled Ductile Cast Iron Components
}

\author{
P. Minnebo, K.-F. Nilsson, and D. Blagoeva
}

(Submitted July 9, 2005; in revised form November 4, 2006)

\begin{abstract}
The article presents the outcome of a comprehensive program of tensile, compression and fracture toughness experiments, addressing thick-walled ductile cast iron inserts used for the production of three nuclear waste canisters. The resulting data are required as input to the assessment of the failure probability of the canisters. Moreover, these data are useful for the improvement of the casting technique as such. Although the same material specification is always used, material properties are found to show significant variation. Considerable attention is paid to linking the scatter in tensile properties to fractographic and microstructural observations. The main finding is that low ductility tensile test results can be primarily connected to the presence of specific casting defects, from which oxide films have the most detrimental effect. Another important observation is that compression experiments do not result in low ductility failure. During fracture testing, stable ductile crack propagation is observed. Basic fracture analysis of a tensile test is performed in order to better understand the effect of defect size, stress-strain behavior and fracture toughness on the ductility measured through tensile testing. Two opposing specimen size effects are observed.
\end{abstract}

Keywords Compression properties, Densely distributed graphite, Ductile cast iron, Finite element analysis, Fracture toughness, Nodularity, Oxide film, Pearlite content, Tensile properties, Thick-walled component

\section{Introduction}

The Swedish concept for deep geological disposal of spent nuclear fuel, KBS-3 (Kärnbränslesäkerhet 3), is based on a multiple barrier principle in order to prevent the release of radionuclides into the environment. The canister that contains the spent fuel is the first and principal barrier within the overall system. Its outer shell consists of $50 \mathrm{~mm}$ thick copper, providing resistance against corrosion and inside is an insert of ductile cast iron in order to guarantee sufficiently high mechanical strength to withstand the pressure under deep disposal conditions. The complete canister, which must remain intact for at least 100,000 years, is nearly $5 \mathrm{~m}$ long and has a diameter of just over $1 \mathrm{~m}$. Figure 1 gives an impression of the boiling water reactor (BWR) nuclear waste canister design (Ref 1).

The work presented in this article was performed in the framework of the collaboration of the Institute for Energy (IE) with the KBS-3 group, which is managed by the Swedish Nuclear Fuel and Waste Management Company (Svensk Kärnbränslehantering-SKB). More specifically the IE was involved in investigations on the failure probability of the canisters and the associated acceptance criteria for the ductile cast iron material properties and the dimensions of casting

P. Minnebo, K.-F. Nilsson, and D. Blagoeva, Joint Research Centre of the European Commission, Institute for Energy, Petten, The Netherlands. Contact e-mail: philip.minnebo@jrc.nl.

defects. This probabilistic study included a variety of experimental and analytical sub-tasks.

The overall objective of the experimental program described in this article was 2-fold. First of all it had to provide input data to the probabilistic failure analysis work mentioned above. This type of analysis requires a number of input parameters, which should be treated as stochastic variables. These variables typically include operating loads and material properties. More specifically the test program had to provide probabilistic distributions for tensile and compression properties and fracture initiation data (Ref 2). A comprehensive series of tests was planned in order to obtain statistically meaningful information for the two failure modes i.e., fracture and plastic collapse. Tensile and compression test data were mainly needed for plastic collapse analyses. Fracture tests were required to determine fracture toughness distributions. In addition to these data, knowledge of the casting defect distribution was needed for the probabilistic analyses. The second goal of the material characterization experiments was to better understand the actual variation in material properties. More particularly the effect of casting defects on the ductile cast iron's ductility had to be closely considered. Low ductility tensile test results had been one of the main problems encountered during the production method development phase of the inserts. Hence, an extensive program of fractographic and metallographic investigations was planned. It is evident that, in a more general context, the large amount of experimental data can also be used to improve the actual casting techniques.

The article is organized as follows. First of all a brief overview of ductile cast iron related aspects is presented. This is followed by a description of the test plan, which addresses three ductile cast iron inserts. Further, tensile and compression data as well as fracture toughness values arising from these inserts are presented and discussed. Next the outcome of fractographic and metallographic investigations on tensile test 


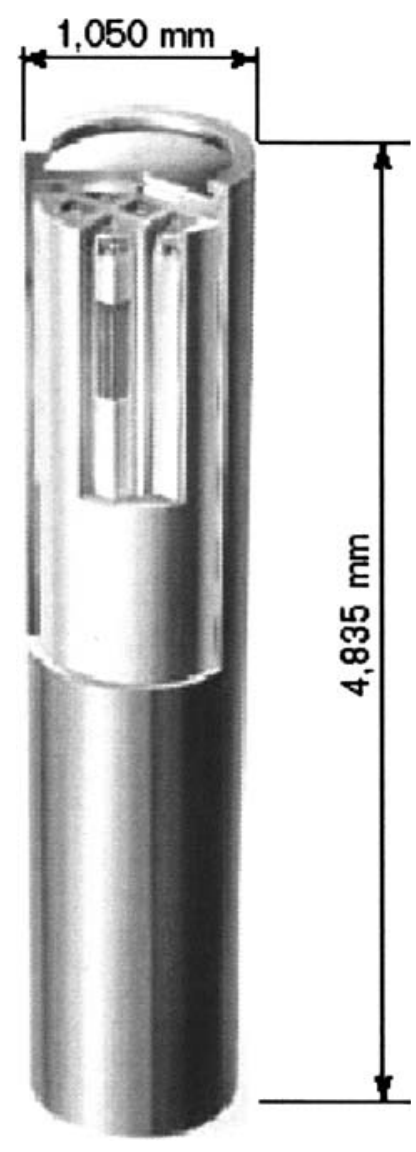

Fig. 1 BWR spent fuel canister design

specimens is considered in detail and finally a basic fracture model of a tensile experiment modeling casting defects is presented.

\section{Ductile Cast Iron}

The production of the KBS-3 inserts is the result of extensive product development, also considering other materials, such as bronze and cast steel. Ductile cast iron was selected because it can be easily procured, it is relatively cheap and it offers the best solution with respect to casting and machiningrelated aspects.

Ductile cast iron is also called nodular iron or spheroidal graphite iron. It is a cast ferrous material in which the free graphite is present in a spherical form. Figure 2 shows a typical microstructure with the graphite nodules in a ferrite and pearlite matrix (Ref 3). Pearlite increases the material's strength but, at the same time, lowers its ductility. Other microstructural parameters affecting the mechanical properties are the general shape of the graphite particles ("nodularity"), the number of graphite nodules (in a metallographic cross-section) per $\mathrm{mm}^{2}$ ("nodule count"), and the overall graphite volume. High nodularity is important, even a limited amount of non-spherical graphite particles will negatively influence mechanical properties. Further, the presence of a variety of casting defects needs to be limited in order to minimize the detrimental effect on the ductile cast iron properties. Possible casting defects include cavities, inclusions, carbides, chunky graphite etc. The control of the casting quality becomes particularly challenging in the case of heavy-section components, such as the KBS-3 canister inserts, and defects cannot be completely ruled out.

National and international standards have been developed providing specifications for the general use of a wide range of ductile cast iron grades. These standard specifications are generally based on mechanical properties, which are essentially (room temperature) tensile data together with impact and hardness requirements. Minimum static fracture toughness figures are not specified in these material standards. The ductile cast iron used in this project is designated EN-GJS-400-15U (number EN-JS1072) in accordance with the European standard EN 1563 (Ref 4). This material acceptance standard requires a minimum level of nodularity and nodule count. The minimum requirements for different wall thickness values with respect to $0.2 \%$ proof stress $\left(R_{\mathrm{p} 0.2}\right)$, ultimate tensile strength $\left(R_{\mathrm{m}}\right)$ and elongation after fracture $(A)$ are given in Table 1 . The EN 1563 standard is a very useful reference but on the other hand it should be stressed that its requirements are not taken over as such within the KBS-3 canister design specifications. First of all the values given in Table 1 are valid for cast-on test bars and second the canister insert wall thickness is over $200 \mathrm{~mm}$ at several locations. Further it should be noted that the canister is mainly designed against compressive loads. Hence, the final material acceptance criteria will depend on several factors specific to this application, including the outcome of probabilistic failure analysis work.

\section{Available Test Material and Experimental Program}

The materials test program was based on three canister inserts, which were produced for R\&D purposes. They were designed to contain BWR spent fuel and referred to as I24, I25,

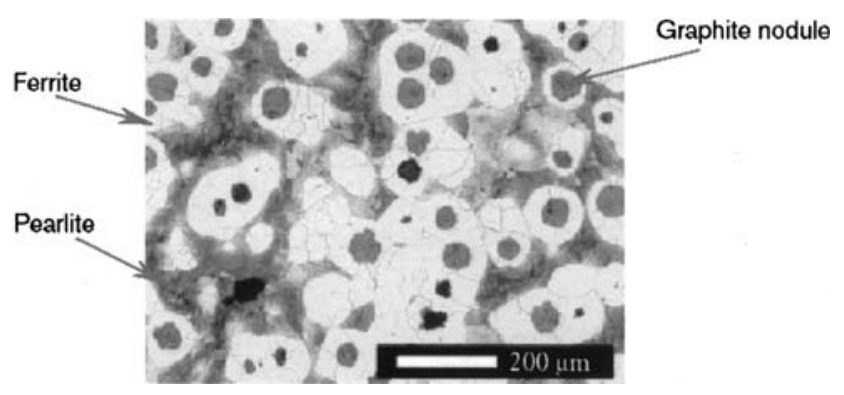

Fig. 2 Typical ductile cast iron microstructure, showing nodular graphite in ferrite and pearlite matrix

Table 1 EN 1563 minimum requirements for $0.2 \%$ proof stress, ultimate tensile strength and elongation after fracture

\begin{tabular}{lccc}
\hline $\begin{array}{l}\text { Relevant wall } \\
\text { thickness t, } \mathbf{~ m m}\end{array}$ & $\begin{array}{c}\mathbf{0 . 2 \%} \text { Proof } \\
\text { stress, MPa }\end{array}$ & $\begin{array}{c}\text { Ultimate tensile } \\
\text { strength, MPa }\end{array}$ & $\begin{array}{c}\text { Elongation after } \\
\text { fracture, \% }\end{array}$ \\
\hline$t \leq 30$ & 250 & 400 & 15 \\
$30<t \leq 60$ & 250 & 390 & 14 \\
$60<t \leq 200$ & 240 & 370 & 11 \\
\hline
\end{tabular}


and I26. The inserts were cast in one single piece of ductile cast iron, which was poured in a mold, filling the spaces in between and around 12 steel channels present to contain the fuel assemblies. The canister inserts were fabricated at three different foundries at an intermediate stage of the casting technique development process. Different production methods were used. For inserts I 25 and I26 bottom pouring casting was applied and insert I24 was produced using a top pouring technique. After casting, the inserts were allowed to cool in the mold for a few days. The inserts were then knocked out of the mold, cleaned, and machined (Ref 1). The chemical analyses corresponding to the three canister inserts are presented in Table 2.

For each canister insert two transverse slabs were cut off for specimen fabrication. One slab was removed from the top region of the insert and included the 12 spent fuel channels. The other segment, which was cut from the bottom, was fully solid. From the top block both "longitudinal" (parallel to the canister symmetry axis) and "transversal" (perpendicular to this symmetry axis) round tensile specimens and Single EdgeNotched Bend (SEN(B)) fracture bars were machined. Also compression test pieces were produced from the top slab. These cylindrical bars were taken out in longitudinal direction. The bottom slab was used in order to produce transversal tensile specimens and SEN(B) bars. Figure 3 shows examples of top and bottom test material blocks, whereas Fig. 4 illustrates the extensive specimen sampling within one of the slabs.

Tensile tests were performed by the IE and by the Swedish Foundry Association (Svenska Gjuteriföreningen-GF) in accordance with the European standard EN10002-1 (Ref 5). In addition to "medium size" tensile bars (Ø $14 \mathrm{~mm})$, also "small" (Ø $9.5 \mathrm{~mm})$ and "large" bars (Ø $20 \mathrm{~mm})$ were tested. This was done in order to check for any specimen size effect, assuming that strength is controlled by the largest inherent defect in accordance with weakest link theory. Compression experiments were carried out at the IE, following the standard ASTM E9-89a (Ref 6). Fracture testing was performed by the IE and at the Swedish Royal Institute of Technology (Kungliga Tekniska Högskolan-KTH). Here ASTM standard E1820-01 was the basis for performing both pre-cracking and the actual fracture experiments (Ref 7). All tests reported in this article were performed at room temperature, which offered the best basis for comparison with available material acceptance criteria. Within the overall experimental program a number of tests were also carried out at 0 and $100{ }^{\circ} \mathrm{C}$ to assess the effect of temperature variations in geological disposal conditions. The resulting data however are not presented here.

\section{Mechanical Test Results}

\subsection{Tensile Properties}

Throughout all the analyses performed, the IE and GF tensile test results were found to show the same trends. Moreover no significant effect was observed from testing different specimen sizes. Consequently all tensile data obtained are treated together in the following discussions.

For each tensile experiment performed at the IE a complete engineering stress-strain curve was recorded. Starting from axial strain measurements it was possible to deduce true stress - true strain curves, at least during uniform elongation, i.e., before necking occurred. These true stress - true strain data were needed for the probabilistic failure analysis of the canisters in order to calculate plastic collapse loads by finite element computations. For insert I25 the tensile curves for different specimens showed little variation until fracture occurred at various stress and strain levels. The same applies for insert I26, which is clearly illustrated by the engineering tensile curves given in Fig. 5. This observation suggested that fracture was caused by defects present in the ductile cast iron. The I24 tensile curves showed more variation, particularly within the insert top region, suggesting microstructural differences in addition to defects. The I26 ductile cast iron reached significantly higher stress levels during the experiments than the I24 and I25 material, as is illustrated in Fig. 6. This observation should be related to the higher Mn level associated with insert I26, which results in higher pearlite content.

Yield strength and flow stress are important material design properties, which are connected to a certain amount of accepted permanent deformation. Depending on the used methodology, a probabilistic failure analysis may require yield strength or flow

Table 2 Chemical analysis (weight percentage) of ductile cast iron used for producing canister inserts I24, I25, and I26

\begin{tabular}{|c|c|c|c|c|c|c|c|c|c|c|}
\hline Canister insert & $\mathrm{C}, \%$ & Si, $\%$ & Mn, $\%$ & $\mathbf{P}, \%$ & $\mathrm{~S}, \%$ & $\mathrm{Cr}, \%$ & $\mathrm{Ni}, \%$ & Мo, \% & $\mathrm{Cu}, \%$ & Mg, \% \\
\hline $\mathrm{I} 24$ & 3.66 & 2.31 & 0.15 & 0.03 & 0.01 & 0.03 & 0.27 & 0.01 & 0.11 & 0.05 \\
\hline $\mathrm{I} 25$ & 3.78 & 2.08 & 0.21 & 0.01 & 0.01 & 0.04 & 0.50 & - & - & 0.04 \\
\hline I26 & 3.56 & 2.39 & 0.52 & 0.03 & 0.01 & - & 0.73 & - & - & 0.06 \\
\hline
\end{tabular}

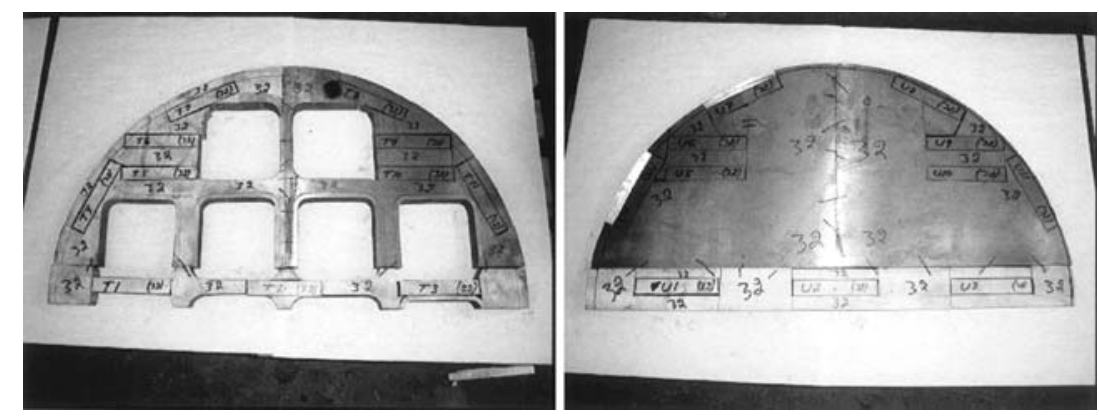

Fig. 3 Top (with channels) and bottom (solid) canister test material blocks 


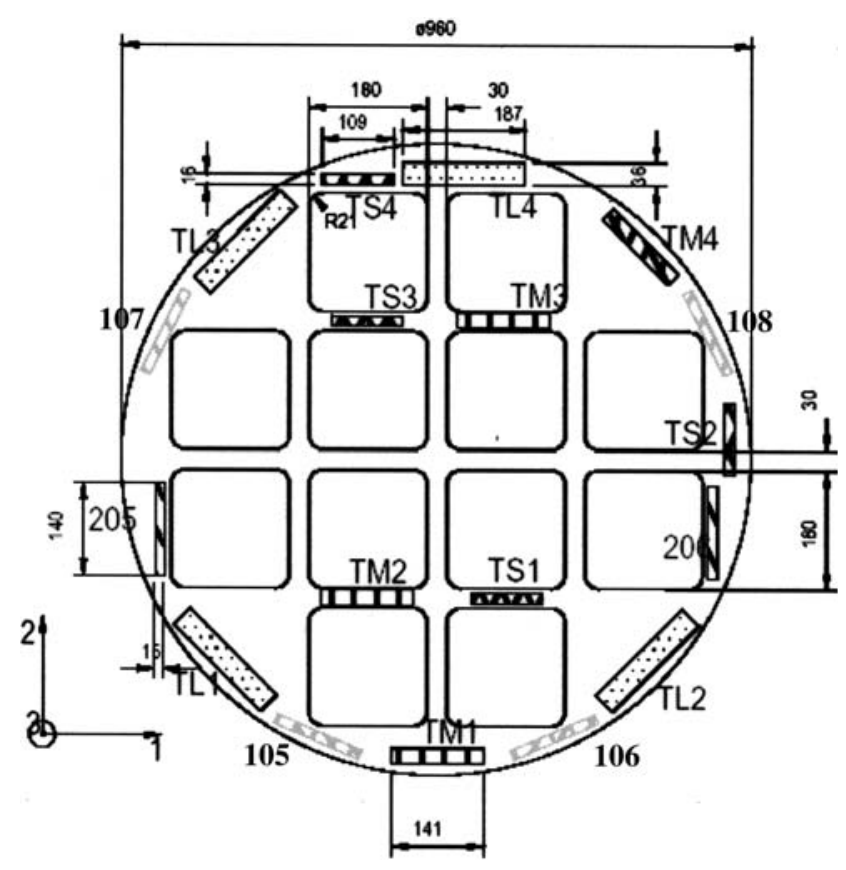

Fig. 4 Example of sampling drawing addressing canister insert top segment

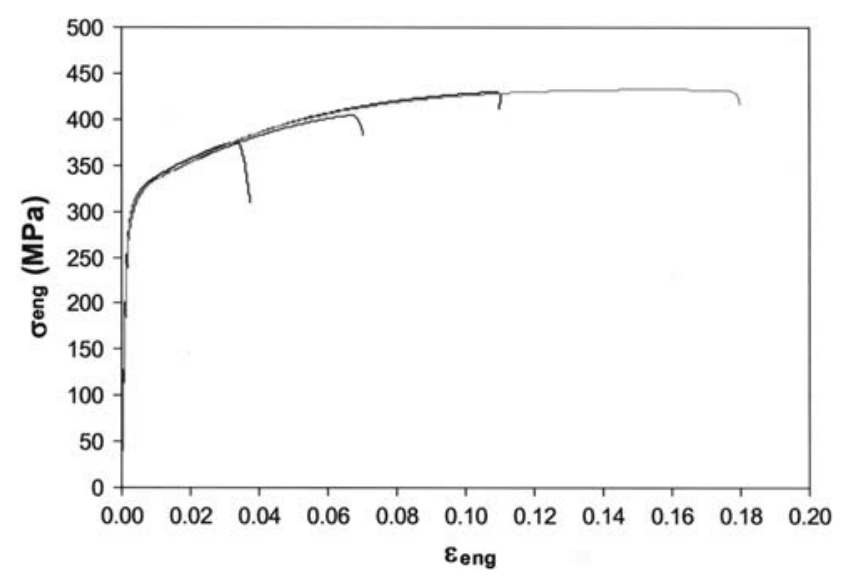

Fig. 5 Engineering tensile curves arising from I26 experiments, showing identical trends until failure occurs at different stress-strain levels

stress as stochastic input variable. As is standard for metallic materials, which do not have a distinctly defined yield point, $0.2 \%$ proof stress was measured, i.e., the engineering stress corresponding to $0.2 \%$ of plastic engineering strain. Table 3 gives the mean values and the standard deviations of the $R_{p 0.2}$ data measured for the three sampling conditions within each insert: top longitudinal, top transversal, and bottom transversal. Figure 7 presents the same information in graphic format; each error bar shown corresponds to the mean value plus and minus one standard deviation (Ref 8 ). The average values observed for insert I26 are clearly higher than those measured for I24 and I25 due to higher pearlite content. For canister I24 the bottom location performed significantly better than the top of the insert, which also gave higher scatter bands. It has to be noted that the various individual data sets (i.e., per sampling condition) generally showed a normal distribution. This was checked by means of the Shapiro-Wilk normality test, which is appropriate for relatively small populations. After having performed an Analysis of Variance (ANOVA), it was even evident that all I26 $0.2 \%$ proof stress data could be considered together as one single normal population (Ref 8). This is illustrated in Fig. 8. The use of flow stress-i.e., the average of $0.2 \%$ proof stress and ultimate tensile strength - in structural integrity analyses allows for higher plastic deformation. These flow stress data $\left(\sigma_{\text {flow }}\right)$ are presented in an identical way as the $R_{\mathrm{p} 0.2}$ results: see Table 4 and Fig. 9. Almost all data sets showed a normal distribution. Also here the bottom part of insert I24 performed remarkably better than the top region, which was in fact the only area resulting in low mean values and higher scatter bands.

Besides properties connected to a certain (limited) amount of allowed plastic deformation, also the failure-related parameter elongation after fracture was closely considered, occasionally in conjunction with ultimate tensile strength. Elongation after fracture is not used as direct input to structural integrity analyses, but it is a good measure for the material's local ductility and - as will be shown below - it is also an excellent indirect measure for the size of casting defects present in a specimen. Figure 10 presents the $R_{\mathrm{m}}-A$ relationship for canister inserts I24 and I26. A clear trend was observed: increasing $A$ values went together with increasing $R_{\mathrm{m}}$ figures until a more or less constant $R_{\mathrm{m}}$ level was reached. Beyond this maximum $R_{\mathrm{m}}$ level, variation of $A$ was still evident. Similar to the observations made for the $0.2 \%$ proof stress, the highest tensile strength

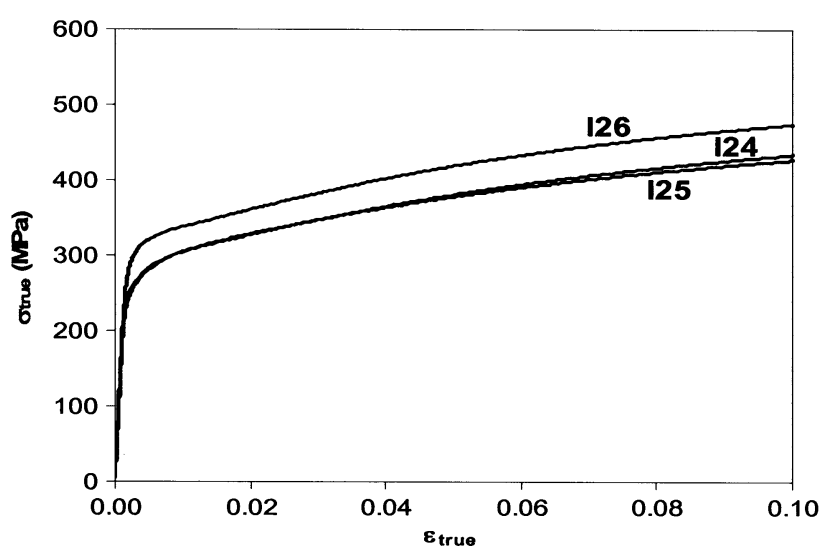

Fig. 6 Typical trends of true stress - true strain curves related to inserts I24, I25, and I26

Table $3 \quad 0.2 \%$ Proof stress $\left(\boldsymbol{R}_{\mathrm{p} 0.2}\right)$ mean values and corresponding standard deviations

\begin{tabular}{llccc}
\hline Insert & \multicolumn{1}{c}{$\begin{array}{c}\text { Sampling } \\
\text { condition }\end{array}$} & $\begin{array}{c}\text { Number } \\
\text { of tests }\end{array}$ & $\begin{array}{c}\boldsymbol{R}_{\mathbf{p 0 . 2}} \text { mean } \\
\text { value, MPa }\end{array}$ & $\begin{array}{c}\boldsymbol{R}_{\mathbf{p 0 . 2}} \text { standard } \\
\text { deviation, } \\
\text { MPa }\end{array}$ \\
\hline \multirow{3}{*}{ I24 } & top longitudinal & 12 & 262 & 8 \\
& top transversal & 21 & 255 & 16 \\
& bottom transversal & 17 & 284 & 7 \\
I25 & top longitudinal & 10 & 262 & 3 \\
& top transversal & 23 & 264 & 4 \\
& bottom transversal & 17 & 261 & 3 \\
& top longitudinal & 8 & 311 & 7 \\
& top transversal & 19 & 313 & 8 \\
\hline
\end{tabular}




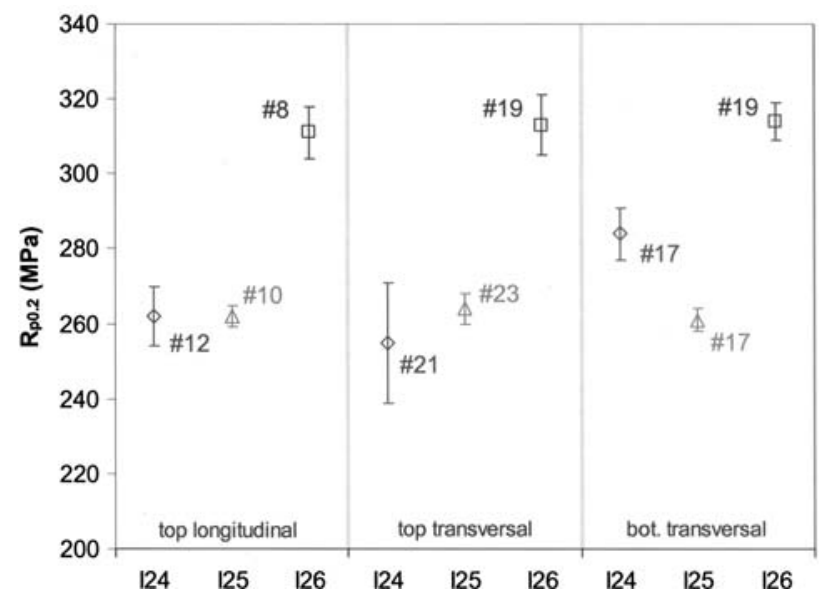

Fig. $7 \quad 0.2 \%$ proof stress mean values and error bars $(= \pm$ standard deviation) as function of 1/canister insert (I24, I25, I26), 2/sampling region (top, bottom) and $3 /$ specimen orientation (longitudinal, transversal)

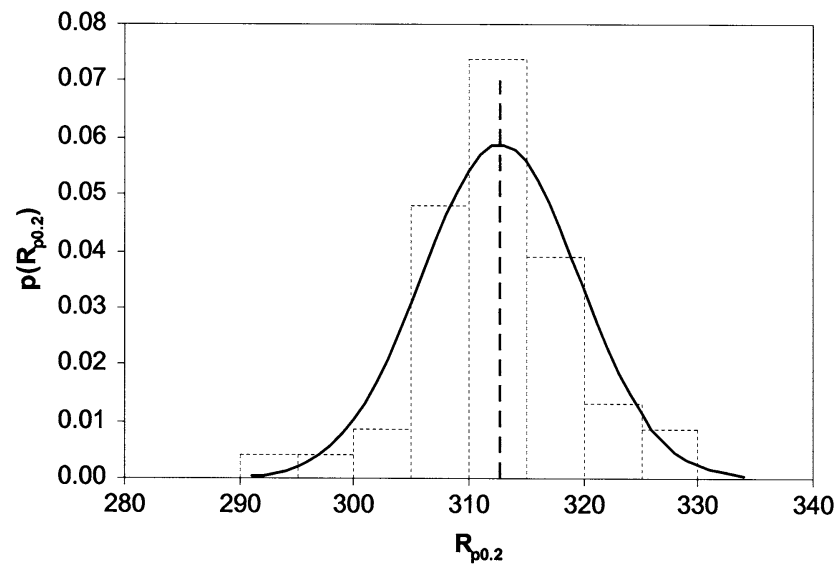

Fig. 8 Canister insert I26 overall $0.2 \%$ proof stress data showing normal distribution

Table 4 Flow stress $\left(\sigma_{\text {flow }}\right)$ mean values and corresponding standard deviations

\begin{tabular}{|c|c|c|c|c|}
\hline Insert & $\begin{array}{l}\text { Sampling } \\
\text { condition }\end{array}$ & $\begin{array}{c}\text { Number } \\
\text { of tests }\end{array}$ & $\begin{array}{c}\sigma_{\text {flow }} \text { mean } \\
\text { value, MPa }\end{array}$ & $\begin{array}{c}\sigma_{\text {flow }} \text { standard } \\
\text { deviation, } \\
\text { MPa }\end{array}$ \\
\hline & top longitudinal & 12 & 290 & 25 \\
\hline \multirow[t]{3}{*}{$\mathrm{I} 24$} & top transversal & 21 & 278 & 23 \\
\hline & bottom transversal & 17 & 345 & 6 \\
\hline & top longitudinal & 9 & 313 & 11 \\
\hline \multirow[t]{3}{*}{$\mathrm{I} 25$} & top transversal & 23 & 316 & 8 \\
\hline & bottom transversal & 17 & 311 & 2 \\
\hline & top longitudinal & 8 & 358 & 12 \\
\hline \multirow[t]{2}{*}{ I26 } & top transversal & 19 & 349 & 15 \\
\hline & bottom transversal & 19 & 362 & 11 \\
\hline
\end{tabular}

was found for I26 due to its higher pearlite content. At the same time this higher pearlite content resulted in lower maximum ductility. Also for the elongation after fracture data, the variation with respect to the sampling location and orientation is shown: see Table 5 and Fig. 11 (Ref 8). Generally, extensive

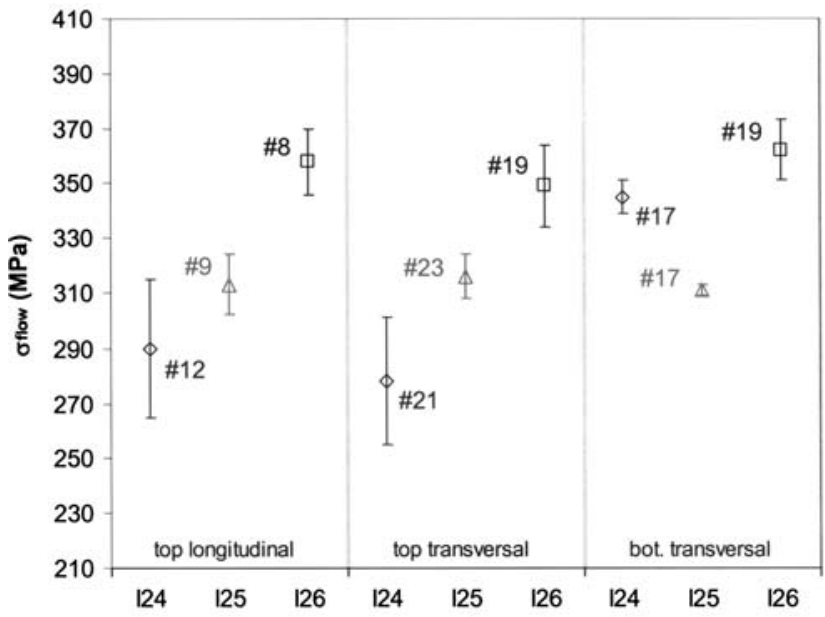

Fig. 9 Flow stress mean values and error bars $(= \pm$ standard deviation) as function of 1/canister insert (I24, I25, I26), 2/sampling region (top, bottom), and $3 /$ specimen orientation (longitudinal, transversal)

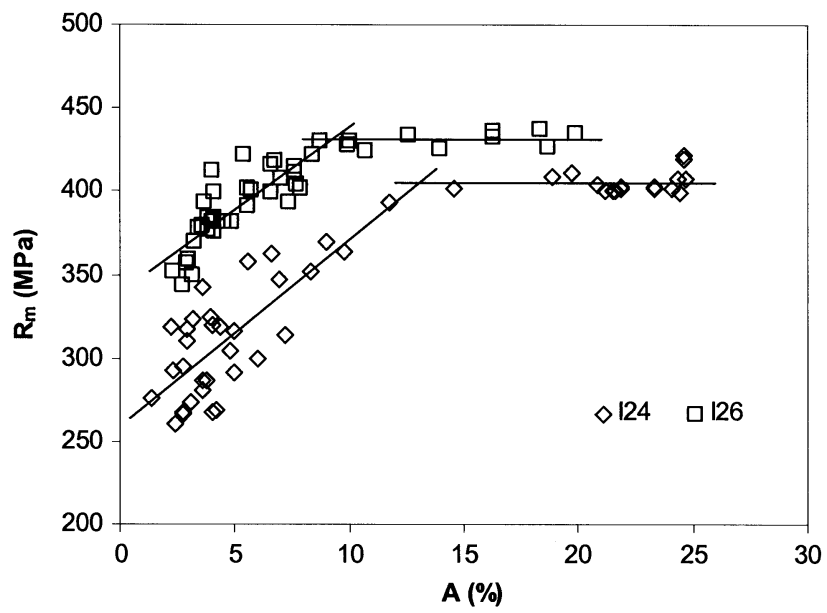

Fig. 10 Ultimate tensile strength as function of elongation after fracture for all I24 and I26 tensile tests

Table 5 Elongation after fracture $(A)$ mean values and corresponding standard deviations

\begin{tabular}{llccc}
\hline Insert & \multicolumn{1}{c}{$\begin{array}{c}\text { Sampling } \\
\text { condition }\end{array}$} & $\begin{array}{c}\text { Number } \\
\text { of tests }\end{array}$ & $\begin{array}{c}\text { A mean } \\
\text { value, \% }\end{array}$ & $\begin{array}{c}\text { A standard } \\
\text { deviation, \% }\end{array}$ \\
\hline \multirow{2}{*}{ I24 } & top longitudinal & 12 & 5.7 & 3.4 \\
& top transversal & 21 & 3.9 & 1.5 \\
& bottom transversal & 17 & 22.1 & 2.6 \\
I25 & top longitudinal & 9 & 12.0 & 4.7 \\
& top transversal & 23 & 10.4 & 3.0 \\
& bottom transversal & 17 & 12.2 & 1.5 \\
& top longitudinal 6 & 8 & 6.7 & 2.2 \\
& top transversal & 19 & 4.5 & 2.3 \\
& bottom transversal & 19 & 9.8 & 5.8 \\
\hline
\end{tabular}

scatter was observed, both between and within the canister inserts. For various locations both low mean values and large standard deviations were found. Concerning I24 a large variation exists between the canister top and bottom results, 
once more with the best results for the bottom. From Table 1 it is obvious that many specimens did not fulfil the standard EN 1563 requirement.

\subsection{Compression Behavior}

As already stated, the canister inserts are mainly designed for compressive loading conditions. For this reason a limited series of compression tests was also carried out. In Fig. 12 the compressive true stress - true strain curves obtained for the three canister inserts are compared with three selected tensile true stress-true strain plots, corresponding to the same sampling orientation (top longitudinal). For the compression tests the curves could always be developed up to high strain values, as no fracture events occurred and because uniform compression within the extensometer gauge length could be assumed throughout the experiments. As was found for tensile testing, the canister insert I26 material resulted in higher compressive stress levels than obtained for inserts I24 and I25,

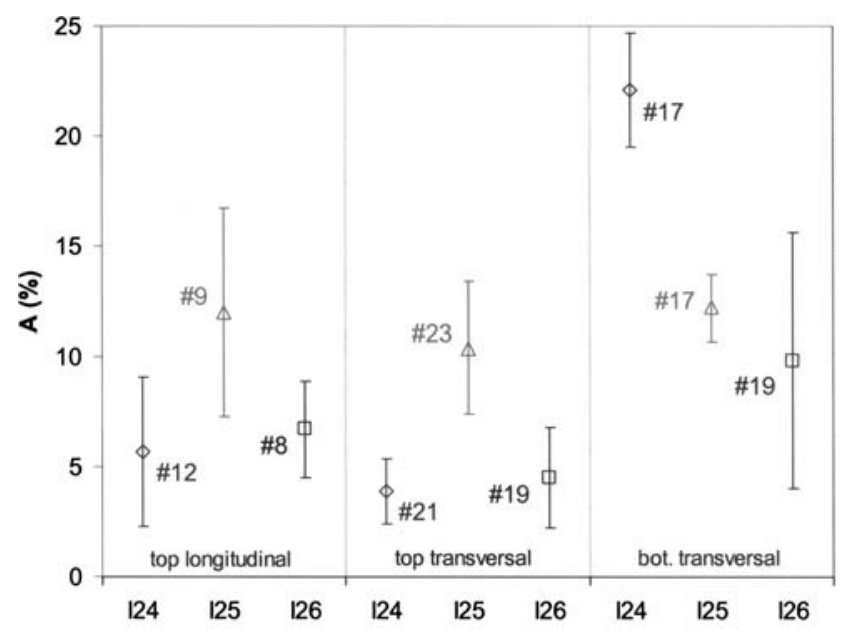

Fig. 11 Elongation after fracture mean values and error bars (= \pm standard deviation) as function of $1 /$ canister insert (I24, I25, I26), $2 /$ sampling region (top, bottom), and $3 /$ specimen orientation (longitudinal, transversal)

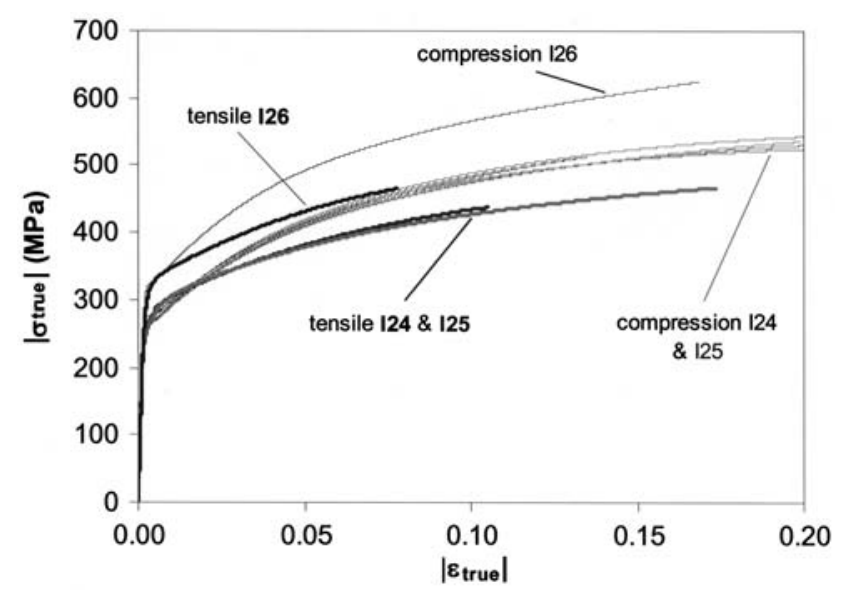

Fig. 12 All compressive true stress-true strain curves measured together with three selected tensile true stress-true strain plots (same sampling orientation) which had comparable compression behavior. It is obvious that the ductile cast iron showed more pronounced strain hardening in compression than in tension, certainly up to true strain values of approximately 5\% (Ref 9). Strain hardening exponents were evaluated using the following Ramberg-Osgood type power law fit (Ref 10):

$\varepsilon_{\text {true }}=\frac{\sigma_{\text {true }}}{E}\left[1+\alpha\left(\frac{\left|\sigma_{\text {true }}\right|}{\sigma_{0}}\right)^{n-1}\right]$

with: $E$ (MPa): Young's Modulus (170,000 MPa for all fits) $n$ : strain hardening exponent $\alpha$ : "yield" offset in the sense that when $\sigma_{\text {true }}=\sigma_{0}, \varepsilon_{\text {true }}=[1+\alpha] \sigma_{0} / E$

The resulting average compressive strain hardening exponents as well as the equivalent tensile values are given in Table 6 . Also the $\sigma_{0}$ figures, which are closely related to the proportional limits, are included. It should be noted however that the Ramberg-Osgood fits were generally quite poor in the yield region.

In Table 7 the average compressive $0.2 \%$ proof stress values are given together with the equivalent tensile values found for the same sampling orientation (top slab, longitudinal direction). It is clear that the compressive values are only slightly higher than those obtained under tensile loading (Ref 9).

\subsection{Fracture Initiation Data}

All specimens, which were tested at the IE, showed stable ductile crack propagation. No brittle fracture events were observed. It must be said that the probability for the presence of

Table 6 Mean compressive Ramberg-Osgood fitting parameters $n$ (strain hardening exponent) and $\sigma_{0}$, together with corresponding tension values from three selected tensile experiments (same sampling orientation: top longitudinal)

\begin{tabular}{llcl}
\hline Insert & R-O parameter & Compression & Tensile \\
\hline $\mathrm{I} 24$ & $n$ & 5.5 & 6.2 \\
& $\sigma_{0}(\mathrm{MPa})$ & 190 & 195 \\
$\mathrm{I} 25$ & $n$ & 5.1 & 6.1 \\
& $\sigma_{0}(\mathrm{MPa})$ & 182 & 136 \\
$\mathrm{I} 26$ & $n$ & $5.2^{\mathrm{a}}$ & 6.7 \\
& $\sigma_{0}(\mathrm{MPa})$ & $207^{\mathrm{a}}$ & 204
\end{tabular}

${ }^{a}$ Only one test was performed

Table $7 \quad 0.2 \%$ Proof stress data resulting from compression experiments together with tensile values related to same sampling orientation (i.e., top longitudinal)

\begin{tabular}{llcr}
\hline Insert & \multicolumn{1}{c}{$\begin{array}{c}\text { Statistical } \\
\text { parameter }\end{array}$} & $\begin{array}{c}\text { Compression } \\
\boldsymbol{R}_{\mathbf{p 0 . 2}}, \mathbf{M P a}\end{array}$ & $\begin{array}{c}\text { Tension } \\
\boldsymbol{R}_{\mathbf{p 0 . 2}}, \mathbf{M P a}\end{array}$ \\
\hline \multirow{2}{*}{ I24 } & Average & 274 & 262 \\
& Standard deviation & 5 & 8 \\
$\mathrm{I} 25$ & Average & 265 & 262 \\
& Standard deviation & 2 & 2 \\
$\mathrm{I} 26$ & Average & $326^{\mathrm{a}}$ & 311 \\
& Standard deviation & $-{ }^{\mathrm{a}}$ & 7
\end{tabular}

${ }^{a}$ Only one test was performed 
a casting defect in the critical material volume around a propagating crack is quite low and that one should expect less variation in fracture toughness than observed for elongation after fracture. A considerable number of specimens showed a highly irregular final crack front - an example is presented in Fig. 13 - and consequently valid $J_{\text {Ic }}$ data could not be derived for these test bars. Nevertheless it was decided to use the results from these experiments and to report the "unqualified" $J_{\mathrm{Q}}$ values for all the tests performed. Table 8 summarizes these $J_{\mathrm{Q}}$ data measured for the three canister inserts at the various sampling positions (Ref 11). Insert I26 shows considerably lower fracture toughness than the other inserts. This should again be related to its higher pearlite content. The actual variation within the inserts was not further investigated with respect to possible fractographic or metallographic features. For the probabilistic analysis addressing a particular canister, the $J$-integral near the onset of crack extension was introduced as one single stochastic variable characterizing the entire insert. For this reason overall mean values and standard deviations

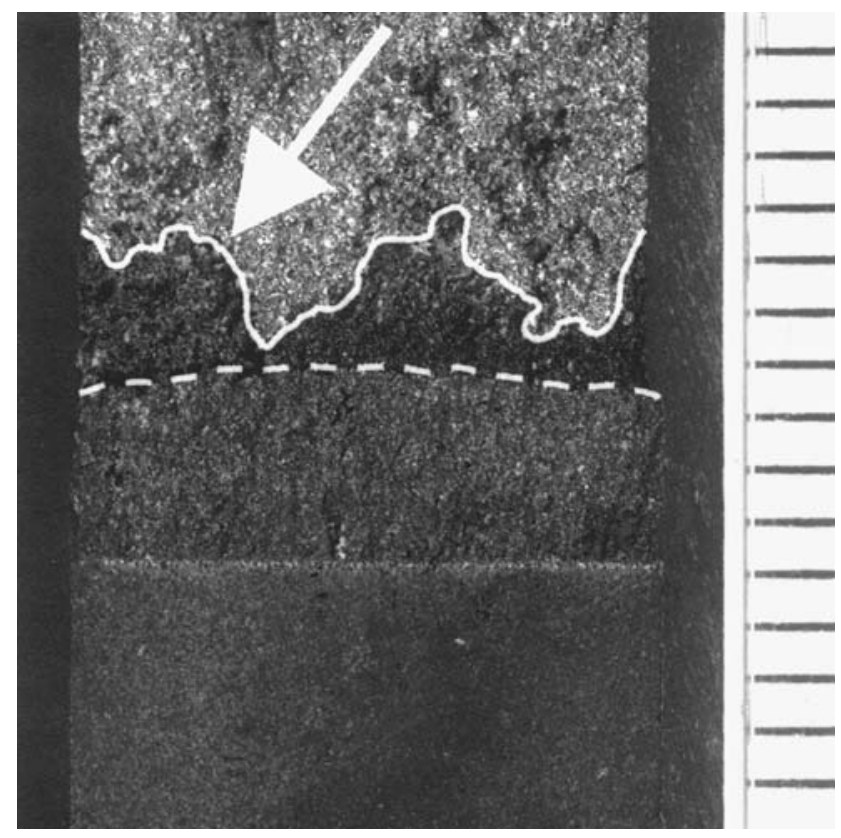

Fig. 13 Fracture surface from insert I24 test specimen, showing irregular final crack front

Table $8 J$-integral values near onset of stable crack propagation (mean values and standard deviations)

\begin{tabular}{|c|c|c|c|c|}
\hline Insert & $\begin{array}{l}\text { Sampling } \\
\text { condition }\end{array}$ & $\begin{array}{l}\text { Number } \\
\text { of tests }\end{array}$ & $\begin{array}{c}J_{\mathrm{Q}} \text { mean } \\
\text { value, } \mathrm{kJ} / \mathrm{m}^{2}\end{array}$ & $\begin{array}{c}\boldsymbol{J}_{\mathrm{Q}} \text { standard } \\
\text { deviation, } \\
\mathbf{k J} / \mathbf{m}^{2}\end{array}$ \\
\hline & top longitudinal & 2 & 44 & 30 \\
\hline \multirow[t]{4}{*}{$\mathrm{I} 24$} & top transversal & 5 & 43 & 8 \\
\hline & bottom transversal & 8 & 45 & 5 \\
\hline & all results & 15 & 45 & 9 \\
\hline & top longitudinal & 2 & 36 & 12 \\
\hline \multirow[t]{4}{*}{$\mathrm{I} 25$} & top transversal & 5 & 41 & 8 \\
\hline & bottom transversal & 9 & 56 & 12 \\
\hline & all results & 16 & 49 & 13 \\
\hline & top longitudinal & 3 & 36 & 2 \\
\hline \multirow[t]{3}{*}{ I26 } & top transversal & 12 & 33 & 4 \\
\hline & bottom transversal & 8 & 30 & 8 \\
\hline & all results & 23 & 32 & 6 \\
\hline
\end{tabular}

have been included in Table 8 . According to a Shapiro-Wilk normality test, the global I24 and I25 data sets show a normal distribution. For insert I26 this is not the case but this is just because of one single low data point.

\section{Fractographic and Metallographic Analyses of Tensile Specimens}

In order to better understand the variations in material properties described in Section 4.1, a comprehensive fractographic and metallographic study was carried out on selected broken tensile specimens. Special emphasis was given to the specimens that had resulted in low elongation after fracture values. All tensile specimens tested by GF (66) were used for microstructural measurements of nodularity and pearlite content. In addition, 36 of these bars were subjected to detailed fractography, which was also the case for 38 IE specimens. A standard scanning electron microscope (SEM) was used for characterizing the fracture surfaces at different magnifications. In addition a number of metallographic cross-sections were produced. These were examined by optical microscopy and in some cases by SEM.

The SEM analysis performed on the tensile specimen fracture surfaces revealed two dominant types of "macroscopic" casting defects, believed to negatively affect the elongation after fracture data. First of all typical zones were observed, which basically consisted of oxides-see Fig. 14. Often $\mathrm{Mg}, \mathrm{Si}$ and $\mathrm{Al}$ inclusions were found inside these oxidized zones. Metallographic cross-sections made from a number of broken specimen halves showed the same type of "opened" oxidized defects under the actual fracture surfaces. This is evident from Fig. 15. These defects should be referred to as "oxide films". They were formed by reoxidation of the metal as it was poured into the mold. The highly reactive metals in the alloy $(\mathrm{Mg}, \mathrm{Al}$ and $\mathrm{Si}-$ see above) reacted with oxygen and formed fresh oxide films. Detailed radiography carried out before the execution of the tensile experiments did not reveal these casting flaws, which apparently were "closed" at that stage of the investigations. It is obvious however that they

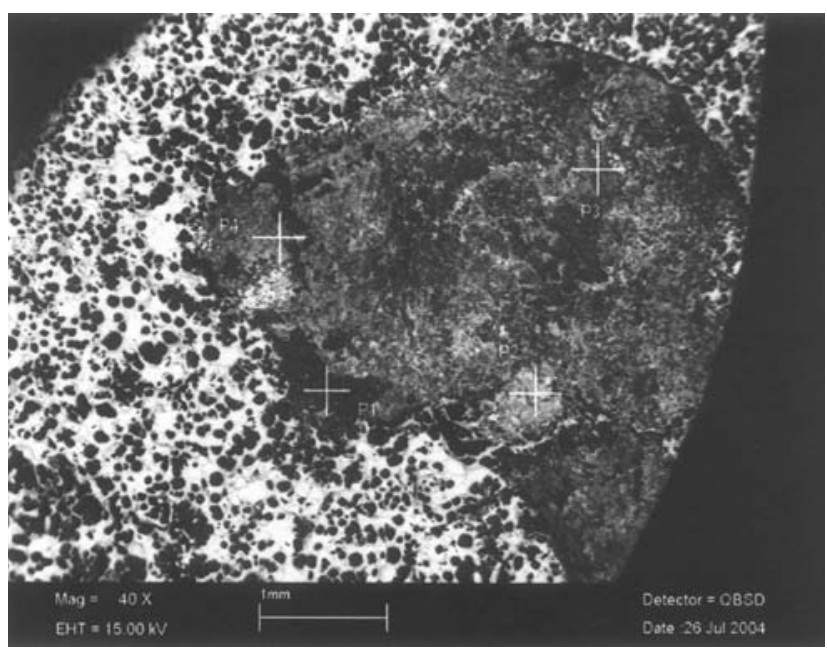

Fig. 14 SEM picture showing typical oxidized defect on fracture surface 


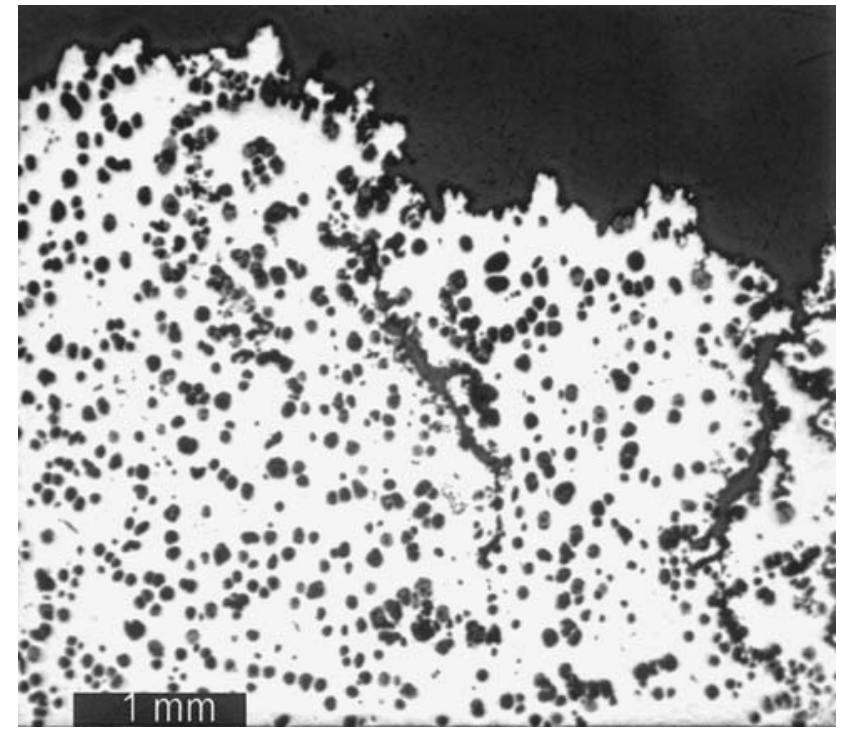

Fig. 15 Opened oxidized defects visible under fracture surface

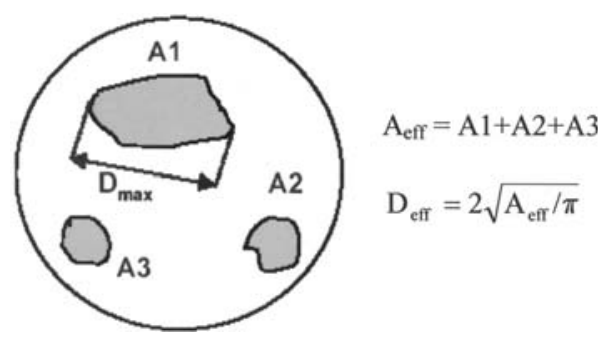

Fig. 16 Definition of effective diameter characterizing oxide film defect

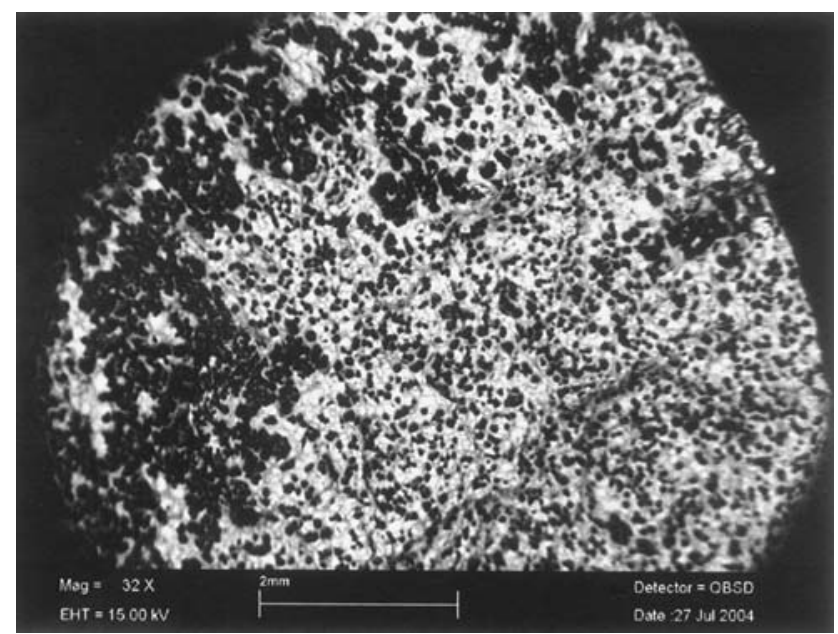

Fig. 17 Area on fracture surface (left side) showing high-density graphite distribution

showed very weak cohesion and opened during the tensile experiments, resulting in premature fracture. The oxide films were treated as cracks and sized through the definition of an effective diameter $\left(D_{\text {eff }}\right)$ as indicated in Fig. 16. The second category of defects detected on the fracture surfaces consisted of regions with densely distributed graphite as shown in

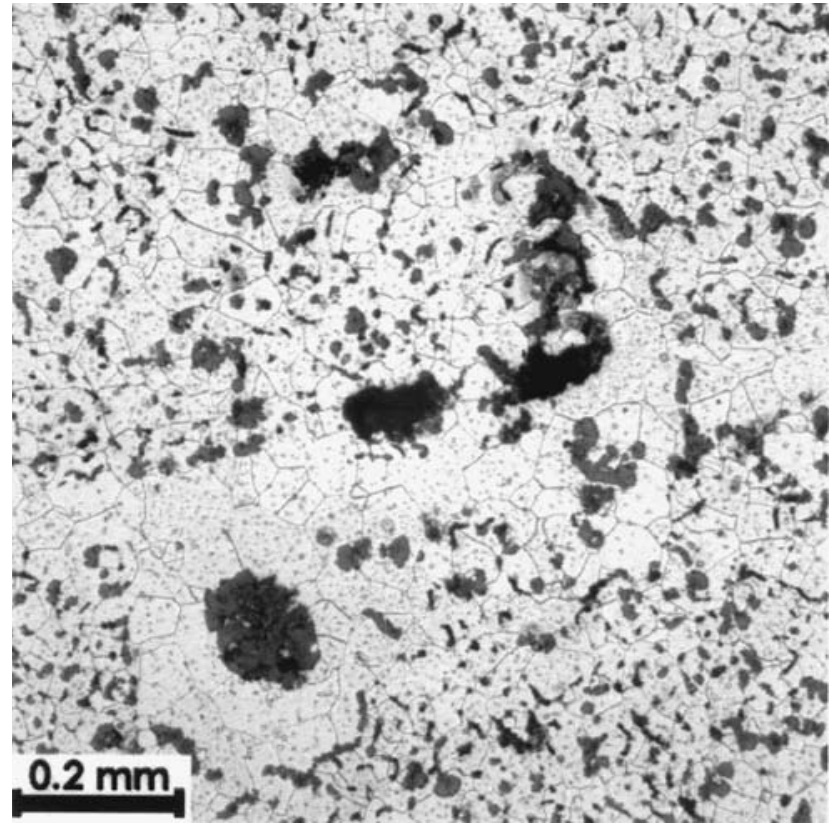

Fig. 18 Example of irregular graphite particles observed in metallographic cross-section

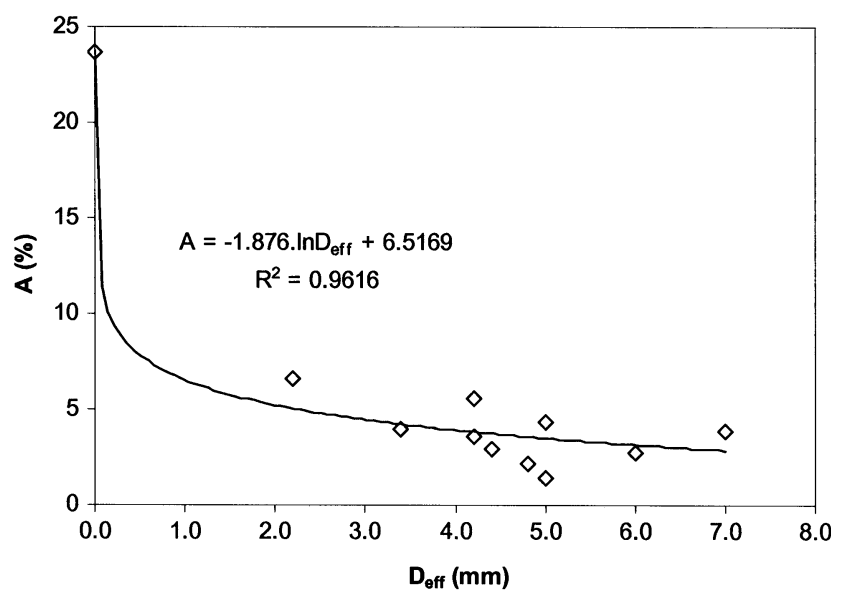

Fig. 19 Elongation after fracture as function of oxide film size, excluding effect of high-density graphite areas

Fig. 17. This defect type appears to be "graphite flotation". Graphite flotation consists of clusters of primary graphite nodules that have separated from the melt, ahead of the eutectic reaction, and have floated to the cope surface or some internal core and become agglomerated. Examination of metallographic cross-sections also revealed the presence of other types of irregular graphite particles, such as "chunky graphite" (Fig. 18), which is caused by excess concentration of rare earth metals. It is important to note that the zones with high carbon density do not act as (sharp) cracks but just merely as areas with lower stiffness and strength. They were sized as a fraction ( $\%)$ of the initial specimen cross-sectional area $\left(\alpha_{\text {eff }}\right)$. In addition to the macroscopic casting defects a number of microstructural features were observed, which are known to partially affect elongation after fracture. The most important were pearlite content and nodularity. It was extremely difficult 
to assess the combined effect of all these factors on the ductility measurements. Nevertheless a number of clear trends could be established, as is shown below.

Canister insert I24 offered an ideal opportunity to investigate the individual effect of the two types of casting defects indicated above, as the pearlite content was practically zero and the nodularity was very high for the entire insert. A multiple logarithmic regression linking the dependent factor A (\%) to the independent variables $D_{\text {eff }}(\mathrm{mm})$ and $\alpha_{\text {eff }}(\%)$ confirmed the dominant effect of the oxide films. A good logarithmic fit was obtained when fracture surfaces only containing oxide films were considered-see Fig. 19. Beyond all it is clear that the presence of the oxide films, even with relatively small dimensions, systematically resulted in low elongation after fracture values, whatever the properties of the other variables were. This is made clear by Fig. 20, which includes all the I24, I25, and I26 oxide film measurements. When really small oxide film dimensions are considered $\left(D_{\mathrm{eff}}<2 \mathrm{~mm}\right)$, the elongation measurements show an increasing trend although the relationship becomes more scattered as the other affecting parameters start to influence A more significantly. An indication of the impact of one of these parameters - the areas with densely distributed graphite-is given by Fig. 21, from which oxide film containing fracture surfaces have been excluded. It is clear that the measured defective area must exceed relatively large values $(\sim 20 \%)$ before a detrimental effect can be observed with respect to the material's ductility.

Regarding microstructural factors, it was found that pearlite content lowered the elongation after fracture measurements, whereas nodularity had the opposite effect. These trends are confirmed to a large extent by Fig. 22 and 23, in which only specimens including very small oxide films are considered ( $\left.D_{\text {eff }}<1 \mathrm{~mm}\right)$. Again it is difficult to come to overall conclusions quantifying all factors together but at least some interesting individual observations can be made, such as:

- the highest elongation value $(24.7 \%)$ is the result of both high nodularity $(90 \%)$ and very low pearlite content $(1 \%)$,

- the difference between two elongation values (9.6 and $19.9 \%)$ corresponding to an identical pearlite content $(5 \%)$ can be explained by a significant difference in nodularity (respectively 60 and $80 \%$ ).

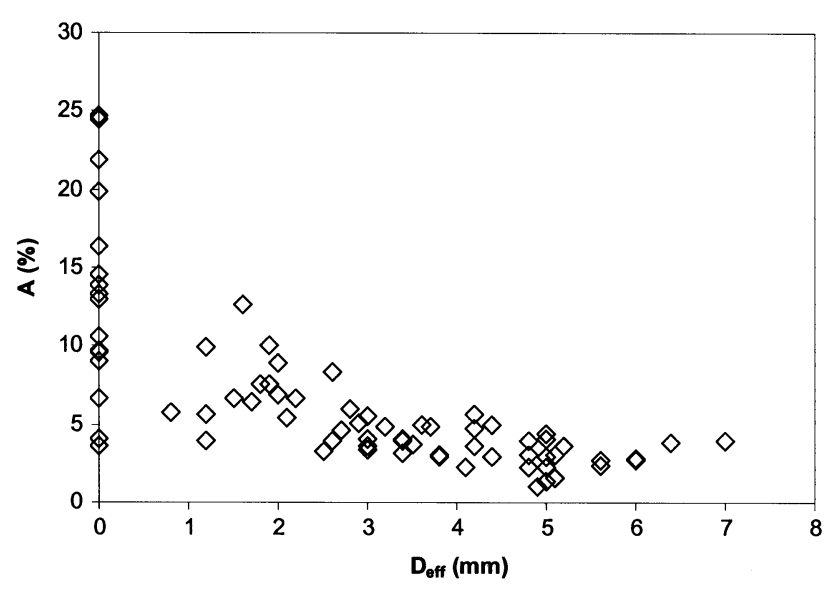

Fig. 20 Relation between elongation after fracture and oxide film size, including effect of other affecting factors (all I24, I25, and I26 data available)

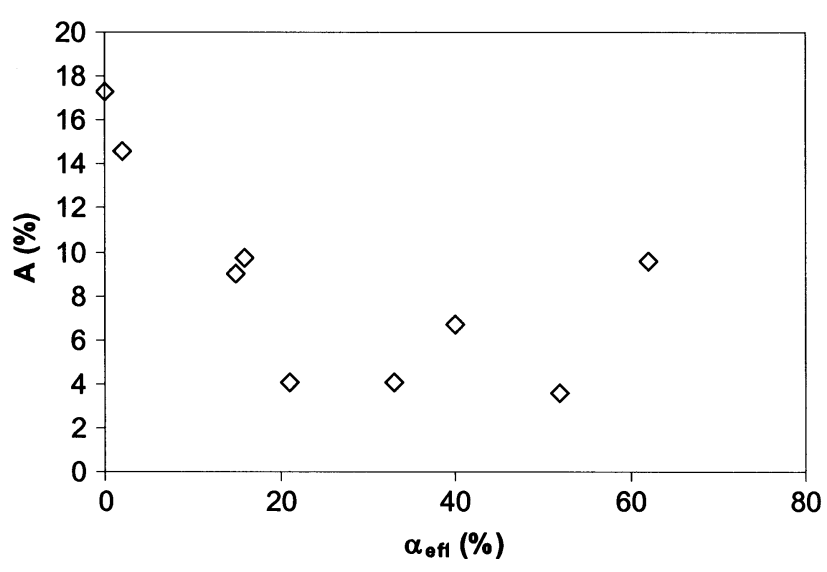

Fig. 21 Relation between elongation after fracture and size of areas with densely distributed graphite, excluding effect of oxide film defects (I24, I25, and I26 data)

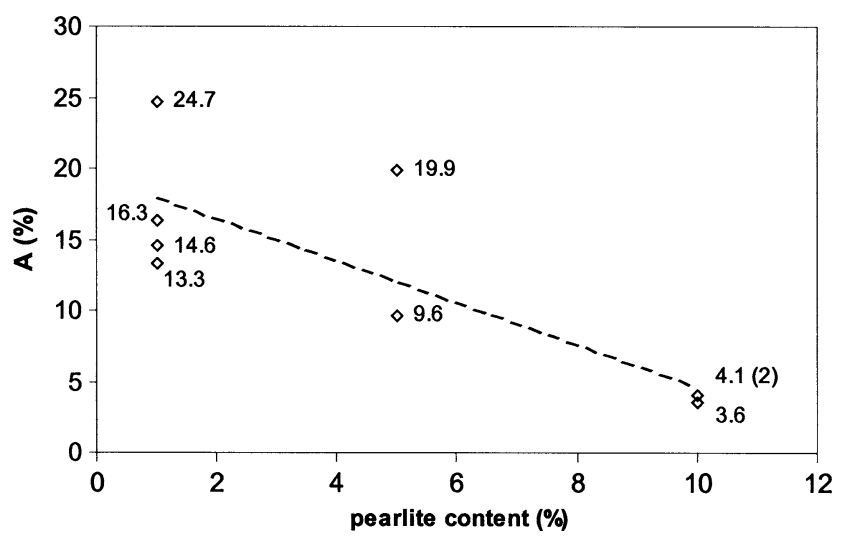

Fig. 22 Relation between elongation after fracture and nodularity, excluding effect of oxide films (I24, I25, and I26 data)

\section{Finite Element Model of Tensile Test}

Elastic-plastic finite element fracture analysis using the commercial code ABAQUS was performed to model fracture of a tensile test. The tensile specimen was modeled as an axisymmetric body with a single penny-shaped crack. Loading was imposed via displacement control. Only the small strain formulation was used in the computation. Figure 24 gives a schematic of the model geometry and the boundary conditions. The finite element mesh was very refined at the crack tip to account for the large local stress and strain concentrations. Moreover the model used the following two idealized assumptions:

- The defect is considered to be flat i.e., crack-like and located transverse to the loading direction. This is expected to reasonably represent the oxide film defects identified on the fracture surfaces. It should be noted however that in reality most defects were volumetric and of spherical shape, which is less critical than sharp cracks from a fracture mechanics viewpoint.

- Only a single defect is assumed, whereas the specimens usually had a large number of defects of various types. 


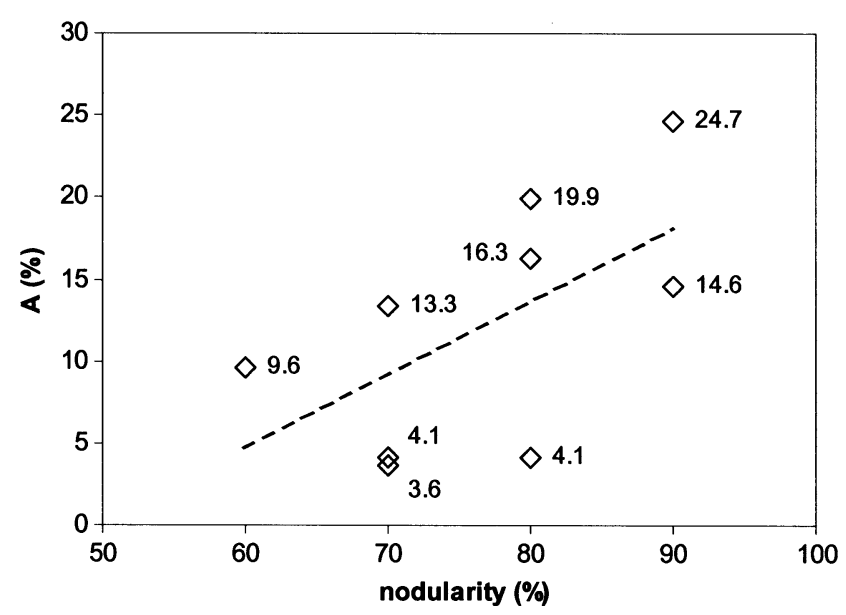

Fig. 23 Relation between elongation after fracture and pearlite content, excluding effect of oxide films (I24, I25, and I26 data)

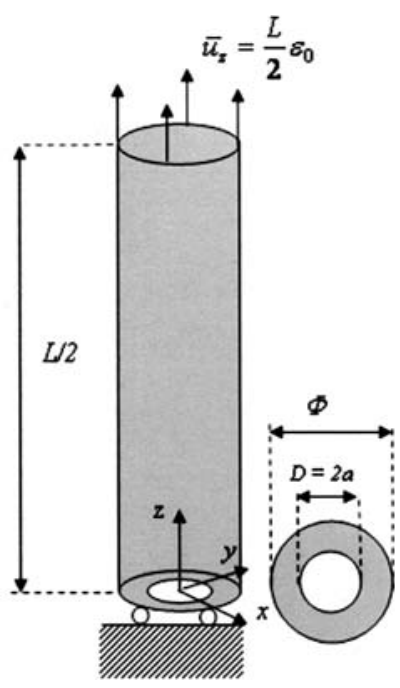

Fig. 24 Illustration of defect and specimen geometry and applied boundary conditions in finite element analysis of tensile tests

Any interaction is expected to be weak for defects not located on the same plane.

The tensile properties were modeled using a Ramberg-Osgood deformation plasticity model-i.e., the same as presented in Section 4.2. - with the parameters fitted to the tensile data given for each insert respectively. $J$-integral values were determined for increasing applied displacements $u_{\mathrm{z}}$ (corresponding strain $\left.\varepsilon_{0}=2 u_{\mathrm{z}} / L\right)$ for models with varying defect diameter $D$. Figure 25 gives the calculated $J-\varepsilon_{0}$ relation for a test specimen diameter $\varnothing=14 \mathrm{~mm}$ and for three distinct $D$ values, this both for insert I24 and insert I26. The effect of the difference in tensile behavior between I24 and I26 is clearly visible, certainly for smaller defect diameters.

A critical strain value strain $\varepsilon_{0}=\varepsilon_{\text {cr }}$ was determined for a specific crack diameter $D$ by calculating the global strain at which the computed $J$ attains the average experimental $J_{\mathrm{Q}}$ value. Figure 26 compares the experimental $A-D_{\text {eff }}$ relationship with the computed $\varepsilon_{\mathrm{cr}}-D$ correlation, again both for the I24 and I26 diameter $\varnothing=14 \mathrm{~mm}$ specimens. Although the correlation is not

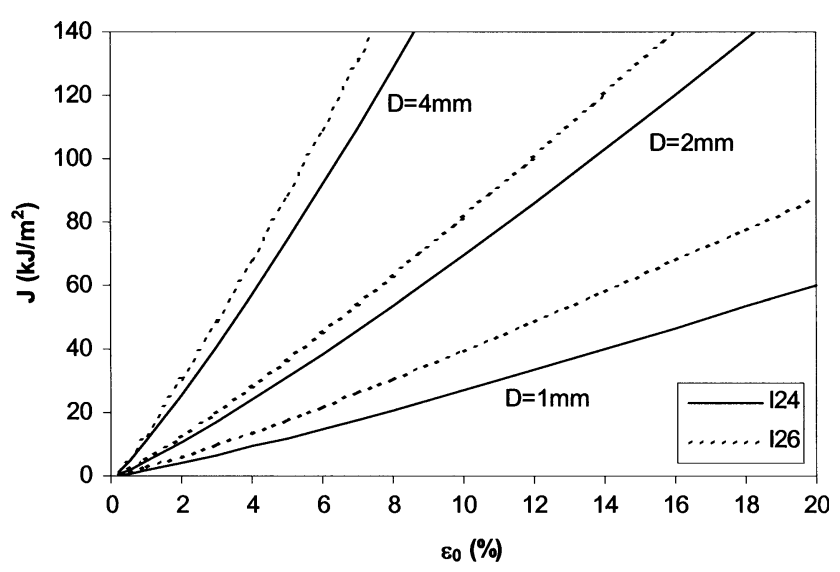

Fig. 25 Computed $J-\varepsilon_{0}$ relationship for test specimen diameter $\varnothing=14 \mathrm{~mm}$ and for three distinct defect diameter $D$ values

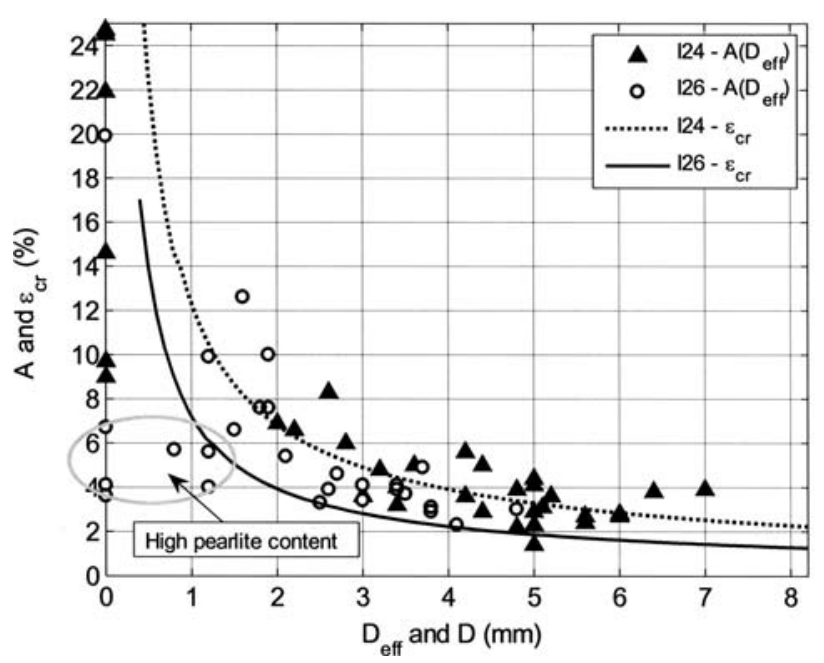

Fig. 26 Comparison of experimental A- $D_{\text {eff }}$ data with computed $\varepsilon_{\mathrm{cr}}-D$ correlation, for $\mathrm{I} 24$ and $\mathrm{I} 26$ diameter $\varnothing=14 \mathrm{~mm}$ specimens

perfect, experimental and computed data generally follow the same trend. In this context one should refer to the idealized assumptions made. It is obvious that the higher strength and lower toughness associated with insert I26 results in lower critical strain (or elongation after fracture) data. (Ref 12)

The probability for having a failure controlling casting defect included in a test specimen increases with the specimen volume. Consequently, in accordance with weakest link theory, the statistically average elongation after fracture data should be lower for large specimens. This size effect was not seen however in the laboratory tests, as mentioned in Section 4.1. This could partly be explained by the higher $J$-values obtained for the smaller specimens $(\varnothing 9.5 \mathrm{~mm})$, given a constant defect diameter. This finding is obvious from Fig. 27, which considers two defect diameters ( 2 and $4 \mathrm{~mm}$ ).

\section{Conclusions}

An extensive program of laboratory experiments was found to be useful to characterize the properties of ductile cast iron 


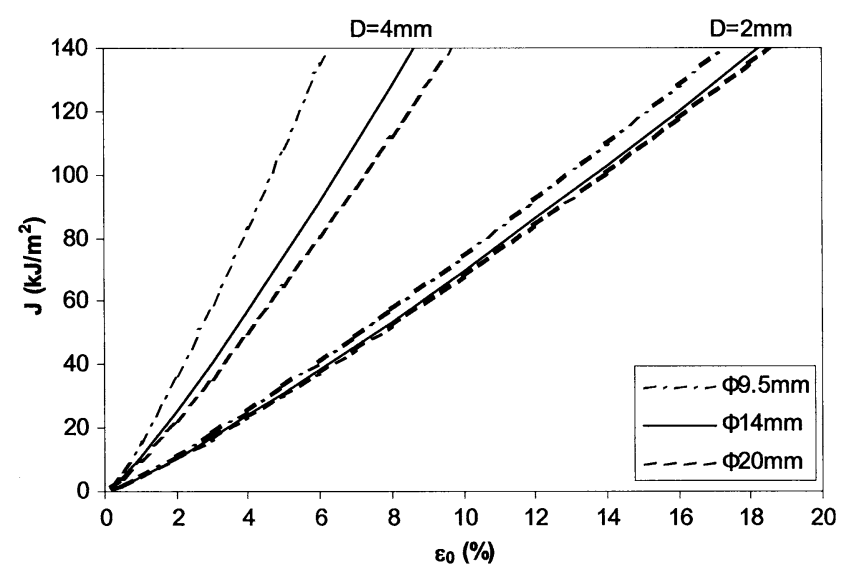

Fig. 27 Effect of tensile specimen diameter $\varnothing$ on $J$ values measured for two distinct defect diameters $D$ (canister insert I24)

used for the fabrication of nuclear waste canister inserts. The resulting data are used as input to the probabilistic failure analysis of the canisters and to improve the casting methodology as such. (Ref 2, 12, 13) The main conclusions from the test program are:

(a) Although the three canister inserts examined were produced in accordance with the same ductile cast iron specification, significant variation was observed regarding the $0.2 \%$ proof stress and the flow stress data. Nevertheless these parameters, which generally showed a normal distribution, basically never dropped to unacceptable low levels. Only the I24 top region material resulted in rather low flow stress data. This observation may be linked to the specific top pouring technique used to produce this canister insert, which gave a lower casting quality at the insert top area, including a concentration of casting defects. The strength increasing effect of pearlite was also obvious.

(b) Special attention was paid to elongation after fracture. The low mean values and the large scatter bands associated with this ductility measure were primarily explained by the presence of casting defects within the canister inserts, i.e., predominantly oxide films. It is obvious that the reduction of these casting defects within the inserts should be the main objective during the further development of the casting technique.

(c) The ductile cast iron showed stable ductile crack growth resistance. Increased pearlite content gave rise to lower fracture toughness.

(d) It should be noted that compressive loads are dominant under deep disposal conditions. Compression experiments did not result in considerably higher $0.2 \%$ proof stress values than those measured through tensile testing. Nevertheless it must be stressed that no low ductility fracture events were observed during the compression tests. Moreover the ductile cast iron showed more pronounced strain hardening than noticed throughout the tensile experiments. (e) Under tensile conditions two opposing size effects were noticed. First of all it is clear that larger material volumes increase the probability for the presence of a critical casting defect. On the other hand, for a given defect size, higher $\mathrm{J}$ values will be reached in smaller component sections. These two effects seem to cancel each other.

\section{Acknowledgments}

The authors would like to acknowledge the support of the KBS3 consortium and in particular the Swedish Nuclear Fuel and Waste Management Company, the Swedish Foundry Association and the Royal Institute of Technology for providing test specimens, complementary experimental data and exchanging useful ideas. Moreover the authors would like to thank the following IE staff members: José Mendes, Pietro Moretto, Franco Di Persio and Nigel Taylor for their appreciated contributions to this article. All the work done at the IE was fully covered by the Joint Research Centre's Institutional Action "SAFE-CASK".

\section{References}

1. C.-G. Andersson, P. Eriksson, M. Westman, and G. Emilsson, "Status Report, Canister Fabrication”, TR-04-23, Svensk Kärnbränslehantering $\mathrm{AB}$, June 2004

2. P. Dillström, "Probabilistic Analysis of Canister Inserts for Spent Nuclear Fuel", TR-05-19, Svensk Kärnbränslehantering AB, October 2005

3. C.-G. Andersson, "Development of Fabrication Technology for Copper Canisters with Cast Inserts, Status Report in August 2001", TR-02-07, Svensk Kärnbränslehantering AB, April 2002

4. "Founding-Spheroidal Graphite Cast Irons", EN1563:1997, European Committee for Standardization

5. "Tensile Testing of Metallic Materials_-Part 1: Method of Test at Ambient Temperature", EN10002-1:1990, European Committee for Standardization

6. "Standard Test Methods of Compression Testing of Metallic Materials at Room Temperature", ASTM Standard E9-89a (reapproved 2000), Annual Book of ASTM Standards 2002 (Section 3, Volume 03.01)

7. "Standard Test Method for Measurement of Fracture Toughness", ASTM Standard E1820-01, Annual Book of ASTM Standards 2002 (Section 3, Volume 03.01)

8. P. Minnebo, "Statistical Analysis of Engineering Tensile Properties of Nuclear Waste Canister Insert Material", EUR21487EN, Joint Research Centre of the European Commission, December 2004

9. P. Minnebo, "Compression Properties of Ductile Cast Iron used for Thick-walled Components", EUR22101EN, Joint Research Centre of the European Commission, December 2005

10. "Mechanical Constitutive Theories-Deformation Plasticity", ABAQUS Theory Manual Version 5.8, Hibbitt, Karlsson \& Sorensen, Inc., 1998

11. P. Minnebo, "Fracture Properties of Ductile Cast Iron used for Thickwalled Components", EUR21841EN, Joint Research Centre of the European Commission, December 2005

12. K.-F. Nilsson, D. Blagoeva, and P. Moretto, “An Experimental and Numerical Analysis to Correlate Variation in Ductility to Defects and Microstructure in Ductile Cast Iron Components", Eng. Fract. Mech., 2006, 73, p 1133-1157

13. C.-G. Andersson et al., "Probabilistic Analysis and Material Characterisation of Canister Insert for Spent Nuclear Fuel", Summary report, TR-05-17, Svensk Kärnbränslehantering AB, November 2005 